\title{
Transatlantica
}

Revue d'études américaines. American Studies Journal

\section{Julian Murphet. Literature and Race in Los Angeles.}

Cambridge : Cambridge UP, 2001. 203 p.

\section{Nathalie Cochoy}

\section{(2) OpenEdition}

Journals

Édition électronique

URL : http://journals.openedition.org/transatlantica/703

DOI : $10.4000 /$ transatlantica.703

ISSN : $1765-2766$

Éditeur

AFEA

Référence électronique

Nathalie Cochoy, « Julian Murphet. Literature and Race in Los Angeles. », Transatlantica [En ligne], 1 ।

2003, mis en ligne le 28 décembre 2009, consulté le 29 avril 2021. URL : http://

journals.openedition.org/transatlantica/703 ; DOI : https://doi.org/10.4000/transatlantica.703

Ce document a été généré automatiquement le 29 avril 2021.

\section{(c) (i) $\odot$}

Transatlantica - Revue d'études américaines est mis à disposition selon les termes de la licence Creative Commons Attribution - Pas d'Utilisation Commerciale - Pas de Modification 4.0 International. 


\title{
Julian Murphet. Literature and Race in Los Angeles.
}

Cambridge : Cambridge UP, 2001. 203 p.

\author{
Nathalie Cochoy
}

1 La ville de Los Angeles est un défi pour les écrivains américains contemporains, non seulement à cause de son expansion désordonnée, de sa fragmentation géographique, sociale, ethnique ou linguistique, mais aussi à cause de l'omniprésence de l'image qui substitue à la « réalité » urbaine une production abstraite et amnésique, encombrée de clichés improvisés par les bâtisseurs de «Tinseltown»-«the imagineers ». Selon Julian Murphet, la littérature de L. A. témoigne de l'anéantissement de la conscience individuelle et collective par 1'appareillage sémiotique et idéologique qui régit le spectacle permanent de la ville. Mais J. Murphet entend aussi montrer que des voix engagées et sonores émergent encore de la machinerie visuelle de L. A. - «'Blades of Grass' waving faintly in the last breath of wind blowing from paradise ». Mobilisant avec une remarquable lucidité les concepts élaborés par Henri Lefebvre, J. Murphet révèle en effet comment les textes littéraires parviennent encore à manifester la présence d'« espaces représentatifs", imaginaires et affectifs, et de "pratiques spatiales ", rituelles ou rythmiques, au sein d'une ville saturée d'images. Loin d'être le miroir d'une réalité divisée et dénaturée, la littérature réinvente un «acte d'appropriation» de l'espace social.

2 Pour éclairer mais aussi dépasser les tensions raciales qui déchirent la ville et les clichés oxymoriques qui la façonnent, Julian Murphet choisit de mettre en parallèle des oeuvres très dissemblables. Rappelant la tradition de résistance culturelle à l'idéologie dominante qui caractérise la littérature de Los Angeles, 1'auteur évoque d'abord le genre du «roman noir», revisité par James Ellroy et Walter Mosley. Il montre ainsi comment, dans les romans d'Ellroy, la scission violemment stéréotypée de l'espace urbain des années cinquante - entre la verticalité arrogante du «Bureau » et de la loi, symbolisée par le City Hall Building, et la dégénérescence rampante de la « rue » et de 1'Autre, incarnée par les quartiers de South Central ou de East L. A. - se trouve 
contestée par le style fiévreusement expérimental de l'auteur. En effet, de même qu'au niveau de la diégèse, la corruption de la police remet en question l'autorité de la loi, de même qu'au niveau du discours, les détours thérapeutiques du côté de l'horreur ébranlent la répartition rationnelle de l'espace, de même, au niveau du style, le mélange des stéréotypes du pouvoir blanc et des rythmes syncopés du jazz noir semble annoncer une rencontre entre l'idéologie centrale et la subversion des marges. Le parallèle entre les romans d'Ellroy et ceux de Mosley est ainsi justifié. Or, si les protagonistes d'Ellroy sont dénués de profondeur, les personnages de Mosley sont des consciences percevantes à part entière. J. Murphet dévoile ainsi le "réalisme latéral » qui, hérité de Chandler, permet à Mosley de s'attarder sur les valeurs d'endurance et de survie qui constituent la communauté afro-américaine. Cependant, toute densité individuelle semble avoir disparu du Los Angeles des années quatre-vingt. Pour des auteurs tels que Bret Easton Ellis ou Dennis Cooper, le voyage au bout de l'extrême, aux confins du morbide et de l'obscène, manifeste la revanche paradoxale du vivant sur le pouvoir hypnotique du visuel. J. Murphet explique ainsi comment le "degré zéro » du style d'Ellis, neutre et répétitif, représente l'irreprésentable vacuité de l'existence - l'invasion paralysante de l'espace intime par la déferlante de messages et d'images qui gouverne la ville. De façon plus subtile encore, J. Murphet dévoile le hiatus étonnant qu'opère Cooper entre les motifs obsessionnels de ses récits - le décryptage sacrilège de corps masculins violés et mutilés - et le sublime maniérisme de son style: « Dennis Cooper's latter-day romanticism achieves, miraculously, the banal sublimity of the true particular, the unassimilable, in an age of purified equivalence ». La poésie s'annonce ainsi comme un mode privilégié de recréation de 1'affect face au fétichisme réifiant et cloisonnant des discours dominants. Optant pour une approche «multiethnique ", J. Murphet explore successivement les poèmes de Wanda Coleman, Luis Rodriguez et Sesshu Foster. A l'aide de micro-analyses claires et convaincantes, il dégage 1'énergie expérimentale et lyrique qui amène la poétesse noire à recourir à d'extravagantes métaphores pour raviver la sensualité du quotidien, le poète chicano à rappeler les pouvoirs unifiants de 1'oralité pour compenser la dispersion du regard, et le poète d'origine chicano-japonaise à allier la polyphonie de sa voix à la plasticité de ses vers pour retrouver une forme d'harmonie au lieu de la dissonance. Loin de subir l'influence pétrifiante de la ville, les poètes manient le verbe pour " produire » l'espace urbain où ils vivent. Telle est également la gageure d'Anna Smith qui, dans son spectacle inspiré des émeutes de 1992, invente un " réalisme anti-réaliste " susceptible de rassembler les voix les plus disparates de L. A. et de recréer les pratiques intimes du corps au sein de l'abstraction urbaine. Imprévisibles et spontanés, le rythme et le mouvement de 1'art performance parviennent à agir directement sur l'espace urbain - à se l'approprier.

3 Rigoureusement démonstratif, agrémenté de rappels historiques documentés, de références théoriques maitrisées (Bakhtine, Barthes ou Deleuze sur le roman, Benjamin, Williams ou Lefebvre sur la ville, Mike Davis sur Los Angeles...) et d'exemples analytiques précis, l'ouvrage de Julian Murphet est une étude originale et passionnante qui marque une nouvelle étape dans l'exploration des rapports entre ville et texte. Remarquablement écrit, Literature and Race in Los Angeles rend également grâce à l'attention minutieuse que 1'auteur porte au style des oeuvres de son corpus - à l'instar d'Ellroy ou de Cooper, il parvient presque à en faire oublier l'insoutenable violence. 
INDEX

Thèmes : Recensions

\section{AUTEUR}

NATHALIE COCHOY

Université Toulouse II 